Inconsistent Time Preferences and On-the-job

Search - When it Pays to be Naive

by

Matthias FAHN

Regina SEIBEL

Working Paper No. 1909

April 2019

Johannes Kepler University of Linz

Department of Economics

Altenberger Strasse 69

A-4040 Linz - Auhof, Austria

www.econ.jku.at

matthias.fahn@jku.at) 


\title{
Inconsistent Time Preferences and On-the-job Search - When it Pays to be Naive*
}

\author{
Matthias Fahn ${ }^{\dagger} \quad \& \quad$ Regina Seibel ${ }^{\ddagger}$
}

March 23, 2019

\begin{abstract}
We study optimal employment contracts for present-biased employees who can conduct on-the-job search. Presuming that firms cannot offer long-term contracts, we find that individuals who are naive about their present bias will actually be better off than sophisticated or time-consistent individuals. Moreover, they search more, which partially counteracts the inefficiencies caused by their present bias.
\end{abstract}

JEL Codes: D21, D83, D90, J31, J32

Keywords: Present bias, on-the-job search

${ }^{*}$ We are grateful to Florian Englmaier, Takeshi Murooka, Nick Netzer, Armin Schmutzler, Peter Schwardmann, Ferdinand von Siemens, as well as seminar participants at the COPE 2018 (Munich) and the annual meeting of the Verein für Socialpolitik 2018 (Freiburg) for valuable comments and suggestions. Financial support by Deutsche Forschungsgemeinschaft through CRC TRR 190 is gratefully acknowledged.

${ }^{\dagger} J K U$ Linz \& CESifo; matthias.fahn@jku.at

$\ddagger$ University of Zurich; regina.seibel@econ.uzh.ch 


\section{Introduction}

People suffer from self-control problems which are often caused by inconsistent time preferences. A huge literature has explored how firms lure consumers or employees into inefficient "exploitative contracts" and thereby extract substantial rents from individuals who are naive about their present bias (see DellaVigna, 2009, or Koszegi, 2014, for overviews).

In this paper, we show that misperceptions of one's future behavior do not necessarily harm employed invidividuals who conduct on-the-job search. Whereas employees with inconsistent time preferences generally search too little from the perspective of earlier periods, those who are naive about their present bias might actually search more and be better off than sophisticated individuals.

Indeed, large numbers of job-to-job transitions indicate that on-the-job search is a significant driver of labor market dynamics. Fallick and Fleischman 2001 report that, in 1999 on average 2.7 percent of employed individuals in the US changed employers every month, and that almost half of new jobs were due to employer changes. Nagypal 2008 shows that in an average month between 1994 and 2007, $2.2 \%$ of all employed workers left for a job with a different employer. Bjelland et al. 2011] find that employer-to-employer flows accounted for around $4 \%$ of total employment in the US between 1991 and 2003.

Search activities on labor markets are mostly perceived to be caused by information frictions which prevent an immediate matching of workers with their optimal job types. There, heterogeneities of workers and jobs have gained considerable attention as main drivers of these frictions (see Pissarides [1994, Mortensen 2000, Moscarini [2005], or Gautier et al. [2010]). But less focus has been put on how the trade-off between costly search effort today and potential benefits later on determines the extent, and consequently stickiness, of the generated inefficiencies. Exceptions are DellaVigna and Paserman 2005] and Paserman [2008], who find that inconsistent time preferences substantially distort the job search behavior of the unemployed.

In this paper, we explore how inconsistent time preferences affect on-the-job search, i.e., search behavior of the employed. We develop a three-period model where a principal hires an agent. The agent receives a wage and can conduct onthe-job search. Wages are determined in every period, with the principal making take-it-or-leave-it offers but being unable to commit to long-term contracts. This assumption differs from many contributions to the job-search literature, where longterm commitment by firms is generally assumed. In a recent contribution, though, Board and Meyer-Ter-Vehn 2015 rule out such long-term commitment in a model of on-the-job search. They are able to generate a number of results that are consistent with empirical observations, for example that workers' retentation rates, motivation, 
and productivities are higher at high-wage firms.

Now, a higher intensity of on-the-job search causes higher search costs for the agent, but also increases the likelihood of receiving an attractive job offer in the next period. Following arguments developed by Pissarides [1992] or Nagypal 2005], and evidence presented by Biewen and Steffes [2010], Mueller [2010], or Cingano and Rosolia [2012], we assume that on-the-job search is more effective than search out of unemployment. Therefore, on-the-job search can also be regarded as a nonpecuniary benefit of employment, which allows for a negative wage premium that pushes the agent's compensation below his outside option (as previously derived by Board and Meyer-Ter-Vehn 2015).

The agent has inconsistent time preference and is present biased. This affects his search intensity, as well as the extent of possible wage reductions due to onthe-job search. The present bias reduces the agent's search effort which, in a given period but from the perspective of earlier periods, is too low for his own taste. This follows results delivered by DellaVigna and Paserman 2005] and Paserman 2008, who show that search effort is significantly reduced if individuals have inconsistent time preferences. Whereas DellaVigna and Paserman [2005] and Paserman [2008] only consider job search out of unemployment, Cho and Lewis [2011] provide anecdotal evidence that a present bias also decreases on-the-job search. They observe a substantial gap between turnover intentions and turnover behavior among employees.

Moreover, our results are crucially affected by the agent's perceptions regarding his own future present bias. The agent can either be sophisticated or (partially) naive (Laibson, 1997, O'Donoghue and Rabin, 1999b, or Eliaz and Spiegler 2006a). Whereas the sophisticated agent perfectly anticipates his future present bias, the (partially) naive agent underestimates its extent. The agent's sophistication matters because inconsistent time preferences affect how wage cuts to exploit the benefits of on-the-job search are timed: The second-period wage completely extracts the agent's expected net benefits from second-period search. But discounting between periods 2 and 3 (when an outside job offer generated by second-period search potentially materializes) is stronger from the perspective of the second than from the perspective of the first period. In period 1, an agent with inconsistent time preferences thus has a strictly positive utility from period-2 search, even taking into account the secondperiod wage. But this is only fully recognized by a sophisticated agent who is hence willing to accept an additional wage reduction in the first period. In contrast, a naive agent does not anticipate his future present bias in period 1 , and consequently does not perceive his period-2 utility to be positive. Therefore, he only accepts a wage reduction that reflects the benefits from period-1 search. All this implies that 
the realized utility of a naive agent at the beginning of period 1 exceeds the utility of a sophisticated agent.

This result has implications for an agent's search effort in the first period. Since the first-period wage is sunk when selecting search effort, a sophisticated agent's perceived utility from staying with the current employer is higher than a naive agent's. Therefore, a naive agent sees a higher net benefit from receiving an outside offer in period 2, which lets him search more extensively than a sophisticated agent.

Concluding, we show that a naive agent is better off than a sophisticated agent, and also searches more (for a partially naive agent, these results are monotone in the extent of his naivete). If on-the-job search indeed reduces matching frictions (what the huge extent of job-to-job flows as described by Fallick and Fleischman, 2001, Nagypal, 2008, or Bjelland et al., 2011 indicates), a higher naivete of employees thus can actually increase the efficiency of labor markets.

Our results stand in stark contrast to most of the literature on present-biased preferences, where naive individuals generally are worse off and generate less efficient outcomes than those who are sophisticated. For example, firms design "exploitative contracts" for consumers who mispredict their own future use of a purchased product. Firms are aware of these misperceptions and charge high prices for letting agents change their plans (see Heidhues and Köszegi, 2010, or Koszegi, 2014 for a survey). In firm-employee contexts such as the present setting, Eliaz and Spiegler [2006b], Gilpatric 2008, or Englmaier et al. 2016 derive related mechanisms. These papers show that naive employees who mispredict their future behavior are exploited by employers and consequently worse off than sophisticated employees. Our paper shows that one has to be careful generalizing these results, in particular if a principal is not able to commit to long-term contracts. Moreover, even if the existence of naive agents increases the welfare of all agents in a market (like Ispano and Schwardmann, 2017), this is driven by the inability of firms to (directly) discriminate between different kinds of agents. In our setting, the principal is aware of an agent's time preferences and therefore able to offer different contracts to different kinds of agents. This forces the principal to make more attractive offers to naive agents, who would otherwise reject the contract due to misperceptions of their future behavior. To conclude, our paper also makes the point that the consequences of regularly-made policy recommendation to protect individuals on labor and product markets might turn out differently than planned. For example, we argue in Section 4 that a minimum wage could harm naive but benefit sophisticated agents, and also reduce the former's search effort.

The paper proceeds as follows. After introducing the model in Section 2, we present the results. As a benchmark, we first derive the contract for a time-consistent 
agent. In Section 3.1, the contract offered to a present-biased but fully sophisticated agent is characterized, followed by the contract offered to a naive agent in Section 3.2. In Section 3.3, we compare outcomes for both types, and take the principal's perspective in Section 3.4. In Section 3.5, we present comparative statics on the extent of the agent's naivete. Finally, we conclude the paper in Section 4 and discuss several implications of our results.

\section{Model Setup}

\section{Environment, Technology \& Contracts}

There is one principal ("she") and one agent ("he") who are active in three periods, $t=1,2,3$. At the beginning of every period, the principal can make a take-it-orleave-it employment offer to the agent. This employment offer consists of a payment, as well as the request to conduct a task that is valuable to the principal. There, we abstract from any incentive problem and assume that, upon acceptance, the agent fulfills the task (for example because his effort is verifiable), and define $w_{t} \in \mathbb{R}$ as the agent's period- $t$ net utility from employment. In the following, we mostly use the term wage when referring to $w_{t}$, however bear in mind that $w_{t}$ not only contains the agent's compensation, but also potential costs of work effort (in contrast to costs of search effort, as defined below).

If the agent rejects the employment offer, he consumes his outside option utility which is normalized to zero. If he accepts the offer, he receives $w_{t}$ but is also able to conduct on-the-job search. More precisely, after accepting the principal's employment offer, the agent chooses his level of search effort, $s_{t} \in[0,1]$. This is associated with search costs $s^{2} / 2$. Furthermore, search effort in period $t$ is identical to the probability with which the agent receives an outside job offer in the subsequent period $t+1$. An outside job offer involves a net benefit of $B>0$ for the agent, and the game ends after such an offer has been accepted. We assume that $B<1$ to make sure that search effort always is strictly below 1. For simplicity and without qualitatively affecting our results, we also assume that $B$ is independent of time, hence the counteroffer - if received - is equally attractive at the beginning of periods 2 and 3 .

Following Board and Meyer-Ter-Vehn 2015], we assume that the principal has no commitment to offer long-term contracts. Furthermore, the agent is only able to conduct on-the-job search, but cannot search after rejecting the principal's offer and being unemployed. Allowing the agent to search while being unemployed would not affect our results, as long as the associated (marginal) search benefits would be 
smaller. Indeed, a number of reasons have been identified for why search by the unemployed might be less effective than on-the-job search. For example, stigma effects could let employers regard unemployment as a negative signal for an individual's ability or motivation (see Biewen and Steffes, 2010, for evidence); network effects might give employed individuals privileged access to information on available employment opportunities (see Cingano and Rosolia, 2012, for evidence); unemployment might cause a decay of human capital (Pissarides, 1992); or firms may prefer to contact already-employed searchers because those are less likely to once again leave for an even more appealing job (Nagypal, 2005). Generally, Mueller [2010] provides evidence that job search is more effective when being employed.

Finally, we assume that the level of the agent's search effort is not verifiable, hence no contract can be based on $s_{t}$.

\section{Preferences}

The agent is risk neutral and discounts future costs and future utilities in a quasihyperbolic way according to Laibson [1997] and O'Donoghue and Rabin [1999a]. Immediate utilities are not discounted. Utilities after $t$ periods are discounted with a factor $\beta \delta^{\mathrm{t}}$, with $\beta \in(0,1]$ and $\delta \in(0,1)$. Hence, an agent's preferences are dynamically inconsistent. This implies that, conditional on accepting the principal's offers, the agent's utility at the beginning of period $t=1$ equals

$$
U_{1}=w_{1}-\frac{1}{2} s_{1}^{2}+\beta \delta\left\{s_{1} B+\left(1-s_{1}\right)\left[w_{2}-\frac{1}{2} s_{2}^{2}+\delta\left(s_{2} B+\left(1-s_{2}\right) w_{3}\right)\right]\right\} .
$$

There, note that the agent will not engage in on-the-job search in period 3 since the game ends afterwards.

In case he has not received an outside job offer, the agent's utility at the beginning of period $t=2$ equals

$$
U_{2}=w_{2}-\frac{1}{2} s_{2}^{2}+\beta \delta\left(s_{2} B+\left(1-s_{2}\right) w_{3}\right)
$$

A comparison of $U_{1}$ and $U_{2}$ reveals the agent's time inconsistency. Whereas discounting between periods 2 and 3 amounts to $\delta$ from the perspective of period 1 , the effective discount factor falls to $\beta \delta$ if evaluated from the perspective of period 2 .

Finally, the agent's utility at the beginning of period 3 - conditional on not having received an outside job offer and accepting the principal's offer - equals 


$$
U_{3}=w_{3} .
$$

The principal is not present biased and discounts future payoffs with $\delta$. If the agent accepts her offer and conducts the task, the principal enjoys a benefit $\pi>0$. The principal's outside utility (which she consumes if the agent rejects her employment offer or receives and potentially accepts an outside offer) equals $\underline{\pi}$, with $\underline{\pi}<\pi . \underline{\pi}$ might include the possibility of finding a new agent, but also potential replacement costs. In the following, we assume $B>(1+\delta)(\pi-\underline{\pi})$, hence making an eventually successful counteroffer is not optimal for the principal. Although successful counteroffers certainly are observed in reality, the mere amount of observed turnover levels in labor markets (as described in the Introduction) indicates that many outside offers are indeed accepted.

\section{Perceptions}

We assume that the agent might be sophisticated or (partially) naive concerning his future present bias. Following Eliaz and Spiegler 2006a], we model partial naivete as frequency naivete: with probability $\theta \in[0,1]$, the period-1 agent perceives his period-2 self to not be present biased; with the remaining probability $1-\theta$, the period-1 agent correctly perceives his period- 2 self to additionally discount future payoffs with $\beta$. The extreme case, $\theta=1$, describes a fully naive agent who thinks that his present bias disappears in the next period with probability 1 , and that he discounts the future exponentially from then on. In contrast, $\theta=0$ describes a sophisticated agent who perfectly anticipates his future present bias. Therefore, a sophisticated agent also correctly predicts his future behavior with probability 1 .

Concerning inter-player perceptions, we assume common knowledge about the principal's time preferences. Moreover, the principal is aware of the agent's present bias. She knows the agent's values $\beta$ and $\theta$, and correctly anticipates potential contradictions between planned and realized actions.

\section{Equilibrium}

Following O'Donoghue and Rabin [1999a and Englmaier et al. 2016], our equilibrium concept is a perception-perfect equilibrium. There, a player's strategy maximizes expected payoffs in all subgames, given one's present preferences, and given one's perceptions of one's own future behavior as well as of the others'. This equilibrium concept enables us to support strategies that are built on a (partially) naive agent's inconsistent beliefs. 


\section{Results}

In the following, we solve for a perception-perfect equilibrium that maximizes the principal's profits. Since the principal cannot commit to long-term contracts, this implies that her profits are maximized at the beginning of every period, and we have to apply backwards induction to solve for equilibrium outcomes. Furthermore, because search-effort is not verifiable, a profit-maximizing equilibrium is equivalent to one that minimizes wage payments $w_{t}$ in every period. We will first characterize equilibria for sophisticated $(\theta=0)$ and fully naive $(\theta=1)$ agents separately (starting with a time-consistent agent as a benchmark), and subsequently compare the two outcomes. Finally, we consider intermediate values of $\theta$.

\section{Benchmark: Time-Consistent Agent}

As a benchmark, we will first derive outcomes for a time-consistent agent (which is equivalent to setting $\beta=1$ ). We start analyzing the third and last period, conditional on the agent not having received an outside job offer before. In $t=3$, the agent will not search, as there is no period thereafter in which he could collect potential search benefits. Furthermore, the principal will offer the lowest wage such that the agent just accepts an employment offer. Therefore, the agent receives (and accepts) a wage offer $w_{3}^{T C}=0$ in period 3, i.e., his net utility of being employed just equals his outside utility of zero.

In the second period, conditional on not having received an outside job offer before, and conditional on having accepted the principal's employment offer, the agent chooses search effort to maximize $-s_{2}^{2} / 2+\delta s_{2} B$, which yields a search level

$$
s_{2}^{T C}=\delta B
$$

Since the agent's benefits from search, $-\left(s_{2}^{T C}\right)^{2} / 2+\delta s_{2}^{T C} B=(\delta B)^{2} / 2$, are strictly positive, and since the agent can only search if he is employed by the principal, the second period wage - the lowest wage still accepted by the agent - equals

$$
w_{2}^{T C}=\frac{1}{2}\left(s_{2}^{T C}\right)^{2}-\delta s_{2}^{T C} B=-\frac{1}{2}(\delta B)^{2}<0 .
$$

Since $w_{2}^{T C}$ is negative, on-the-job search can be regarded as a non-pecuniary benefit of being employed that allows the principal to reduce the second-period wage below the agent's reservation utility (as previously derived by Board and Meyer-TerVehn, 2015). At the beginning of period 2, taking into account $w_{2}^{T C}$ and expected search benefits, the agent's utility equals his reservation utility of zero. Thus, the situation in the first period is equivalent to the second period, which implies that 
outcomes coincide as well. Lemma 1 collects the results for the benchmark case of a time-consistent agent.

Lemma 1 A time consistent agent

- exerts the same search effort in periods 1 and 2, i.e. $s_{1}^{T C}=s_{2}^{T C}$

- receives the same wage in periods 1 and 2, i.e. $w_{1}^{T C}=w_{2}^{T C}<0$. These wages are equal to the respective period's negative search benefit.

The proof can be found in the Appendix.

\subsection{Sophisticated Agent}

In a next step, we analyze outcomes for a present-biased but sophisticated agent. Now, the agent's perceived trade-off between search costs and search benefits depends on the point of time when it is assessed. This gives the principal additional, intertemporal, opportunities to reduce wages.

In period 3, if still employed by the principal, a sophisticated agent will also conduct no search and receive a wage of $w_{3}^{S}=0$. In period 2 , his search effort maximizes $-s_{2}^{2} / 2+\beta \delta s_{2} B$, which yields a search level

$$
s_{2}^{S}=\beta \delta B
$$

Naturally, search effort incorporates the lower discount factor $\beta \delta<\delta$. The period-2 wage $w_{2}^{S}$ again takes into account that search is only possible for the agent if being employed, and is set to satisfy $U_{2}^{S}=w_{2}^{S}-\left(s_{2}^{S}\right)^{2} / 2+\beta \delta\left(s_{2}^{S} B+\left(1-s_{2}^{S}\right) w_{3}^{S}\right)=0$. Thus,

$$
w_{2}^{S}=\frac{1}{2}\left(s_{2}^{S}\right)^{2}-\beta \delta s_{2}^{S} B=-\frac{1}{2}(\beta \delta B)^{2}<0 .
$$

As with a time-consistent agent, the wage of a sophisticated agent can be reduced below his outside option because the option to search is an additional benefit of being employed. However, a time-inconsistent agent's evaluation of his future payoffs is different from the perspective of period 1 than it is from the perspective of period 2. This drives our next results, which are collected in Lemma 2 ,

Lemma 2 Assume $\theta=0$, i.e., the agent is present-biased but sophisticated. Then,

- search in the first period is lower than in the second period, i.e. $s_{1}^{S}<s_{2}^{S}$

- the first-period wage is lower than the first-period negative search benefit, i.e. $w_{1}^{S}<\frac{1}{2}\left(s_{1}^{S}\right)^{2}-\beta \delta s_{1}^{S} B$. 
The proof can be found in the Appendix.

From the perspective of period 1, discounting between periods 2 and 3 amounts to $\delta$, whereas the discount factor from the perspective of period 2 equals $\beta \delta$. This changes the relative assessment of costs and benefits of second-period search. Thus, although $w_{2}^{S}$ fully extracts the agent's net utility from search in period 2, it does so only from the perspective of period 2. But due to his present bias, the agent's secondperiod search benefit in relation to his search costs is higher from the perspective of period 1 than it is from the perspective of period 2. Plugging $w_{3}^{S}=0$ and $w_{2}^{S}=\frac{1}{2}\left(s_{2}^{S}\right)^{2}-\beta \delta s_{2}^{S} B$ into the agent's period-1 utility yields

$$
U_{1}^{S}=w_{1}-\frac{1}{2}\left(s_{1}\right)^{2}+\beta \delta\left[s_{1} B+\left(1-s_{1}\right) \delta s_{2}^{S} B(1-\beta)\right]
$$

There, the last term, $\left(1-s_{1}\right) \delta s_{2}^{S} B(1-\beta)$, captures the "extra" utility of period-2 search when assessed from the perspective of earlier periods.

This yields two implications for period-1 outcomes. First, compared to the time-consistent agent, $w_{1}^{S}$ is not only reduced by period- 1 search benefits, but also by the agent's "extra" period-2 search benefits, as regarded from the perspective of period 1. Second, because the agent only enjoys these future search benefits if he continues to stay employed by the principal and does not receive an outside job offer, his incentives to conduct on-the-job search are reduced in comparison to period 2.

Finally, note that in period 2 but regarded from the perspective of period 1 , the agent searches "too little" for his own taste $(\delta B$ versus $\beta \delta B)$. This confirms that the results DellaVigna and Paserman 2005 and Paserman [2008] have derived for search out of unemployment also hold for on-the-job search.

\section{$3.2 \quad$ Fully Naive Agent}

Now, we assume that the agent is present biased but fully naive about his time inconsistency. This implies that $\theta=1$, i.e., in period 1 the agent expects his present bias to disappear from period 2 on.

As with a sophisticated (and a time-consistent) agent, the period-3 wage of the naive agent equals $w_{3}^{N}=0$. Furthermore, upon not having received an outside job offer, but having accepted the principal's employment offer, the naive agent's effective search effort in period $t=2$ also maximizes $-\left(s_{2}\right)^{2} / 2+\beta \delta s_{2} B$, yielding a search level

$$
s_{2}^{N}=\beta \delta B
$$


Furthermore,

$$
w_{2}^{N}=\frac{1}{2}\left(s_{2}^{N}\right)^{2}-\beta \delta s_{2}^{N} B=-\frac{1}{2}(\beta \delta B)^{2}<0 .
$$

Whereas $w_{2}^{N}=w_{2}^{S}$ and $s_{2}^{N}=s_{2}^{S}$, the naive agent does not anticipate these outcomes in period 1 . There, he expects to be an exponential discounter from period 2 on and therefore maximize $-\frac{1}{2}\left(s_{2}\right)^{2}+\delta s_{2} B$. This implies that, from the perspective of period 1 , the agent perceives to choose a search level $\tilde{s}_{2}^{N}$ which is characterized by

$$
\tilde{s}_{2}^{N}=\delta B
$$

Because $\tilde{s}_{2}^{N}>s_{2}^{N}$, the agent overestimates his future search effort. As a consequence, in period 1 the naive agent underestimates his period-2 wage. He expects to be offered a wage $\tilde{w}_{2}^{N}=\left(\tilde{s}^{N}\right)^{2} / 2-\delta \tilde{s}^{N} B$, which turns out to be smaller than the second-period wage he is effectively willing to accept, $w_{2}^{N}$.

The naive agent's behavior in $t=1$ is thus determined by his perceptions of future outcomes, not their true realizations:

Lemma 3 Assume that $\theta=1$, i.e., the agent is present-biased but fully naive. Then,

- search efforts in the first and second period are equal, i.e. $s_{1}^{N}=s_{2}^{N}$

- the first-period wage is equal to the first-period negative search benefit, i.e. $w_{1}^{N}=\frac{1}{2}\left(s_{1}^{N}\right)^{2}-\beta \delta s_{1}^{N} B$.

The proof can be found in the Appendix.

From the perspective of period $t=1$, the naive agent expects to have a period-2 net utility of zero. The principal thus is not able to collect the additional search benefits that stem from the agent's time inconsistency. Note, however, that his real period-2 payoff - regarded from the perspective of period $t=1-$ is positive. We will explore this aspect and the differences between naive and sophisticated agent in detail in the next section.

\subsection{Comparison}

Now, we compare outcomes of a fully naive $(\theta=1)$ and a sophisticated $(\theta=0)$ agent. First, recall that $s_{2}^{S}=s_{2}^{N}$ as well as $w_{2}^{S}=w_{2}^{N}$ and $w_{3}^{S}=w_{3}^{N}$. Therefore, realized outcomes in periods two and three are identical. However, $s_{2}^{S}<\tilde{s}_{2}^{N}$ and $w_{2}^{S}>\tilde{w}_{2}^{N}$. This difference in anticipated behavior lets period-1 search effort and wages of a naive and a sophisticated agent differ. 
Proposition $1 s_{1}^{N}>s_{1}^{S}$, i.e. the period-1 search effort of a naive agent is higher than of a sophisticated agent.

The proof can be found in the Appendix.

From the perspective of period 1, a sophisticated agent perceives his period-2 net utility from staying with the principal to be positive, whereas a naive agent (wrongly) perceives it to be zero. Thus, the relative marginal benefits of obtaining an outside job offer are higher for the latter, who consequently searches more.

Interestingly, a naive agent's wrong perception of his future behavior actually counteracts his present bias - which originally lets him search "too little" due to a stronger focus on today's costs compared to tomorrow's benefits.1 Therefore, if search generally increases the efficiency of the labor market - as opposed to merely letting the agent keep a larger share of the surplus - a naive agent generates a higher surplus than a sophisticated agent. Indeed, the sheer amount of job-to-job flows (see Fallick and Fleischman, 2001, Nagypal, 2008, or Bjelland et al., 2011), combined with the observation that switching employees experience substantial earnings growth (Haltiwanger et al., 2014, Hahn et al., 2017), indicates that on-the-job search reduces frictions and improves matching between firms and employees

In a next step, we show that naive agents are also better off than sophisticated or time-consistent agents. Thereby, we compare realized and not perceived utility levels. First, note that realized utility levels at the beginning of period 2 are the same for all types of agents, namely $U_{2}^{S}=U_{2}^{T C}=U_{2}^{N}=0$. In the first period, the sophisticated and time-consistent agent also have realized utilities $U_{1}^{S}=U_{1}^{T C}=0$, whereas the naive agent only perceives his utility level to be $\tilde{U}_{1}^{N}=0$. His realized utility, however, is higher.

Proposition 2 The naive agent realizes a strictly positive utility level from the perspective of period $1, U_{1}^{N}>0$. Therefore, in terms of realized outcomes, a naive agent is strictly better off than a sophisticated or a time-consistent agent.

The proof can be found in the Appendix.

In periods 2 and 3, all types of agents exert the same search effort and end up getting the same wages. Only a naive agent's first-period wage is larger (in relation to search benefits) than the wages of a sophisticated or a time-consistent agent. Again, this is because a naive agent's perceived period-2 utility from the

\footnotetext{
${ }^{1}$ We could formally derive this result by extending the number of periods, for example by introducing a "period zero" where we evaluate all future outcomes given the agent's preferences in this period zero.
} 
perspective of the first period is zero, whereas it actually is strictly positive. A naive agent thus underestimates his total utility, and will only later on recognize this unexpected rent.

Our results differ from much of the literature on inconsistent time preferences. There, naive consumers and/or employees are generally worse off than sophisticated ones. The reason is that firms design exploitative contracts, where individuals pay high prices for changing their plans. Since naive agents have wrong perceptions of their future actions, they willingly sign these exploitative contracts which seem attractive if one does not anticipate a change of future actions. ${ }^{2}$ We argue that this picture is not complete and that one should be careful making policy recommendations to protect naive individuals, in particular if firms are not able to commit to future contracts.

\subsection{Principal}

Now, we compare the principal's payoffs when employing a sophisticated agent to the case of employing a naive agent. Recall that $B>(1-\delta)(\pi-\underline{\pi})$, where $\pi$ is the principal's per-period payoff from keeping the agent, and $\underline{\pi}$ her per-period payoff after losing the agent. Hence making a (sufficiently high) counteroffer would not be profitable.

From the second period onwards, naive and sophisticated agent are identical in terms of search effort and wages, thus the relative benefits to the principal are solely determined by first-period outcomes.

Proposition 3 The principal's profits with a sophisticated agent are higher than with a naive agent.

The proof can be found in the Appendix.

The principal prefers to employ a sophisticated agent who receives a lower wage and conducts less search in the first period. The latter increases profits because $\pi>\pi$

\subsection{Partially Naive Agent}

Finally, we explore the case of a partially naive agent, that is, an agent who perceives the probability of being an exponential discounter in future periods to be $\theta \in(0,1)$.

\footnotetext{
${ }^{2}$ See Koszegi 2014 for a survey on exploitative contracts in an IO context. Eliaz and Spiegler 2006b, Gilpatric 2008, or Englmaier et al. 2016 analyze settings more related to ours, where firms exploit employees' misperceptions regarding their future behavior.
} 
We show that a lower $\theta$, i.e., more sophistication, monotonously reduces search as well as the agent's realized utility level.

Outcomes in periods two and three are independent of $\theta$, hence the same as with a sophisticated and fully naive agent. From the perspective of period 1, a partially naive agent expects to maximize $-\left(s_{2}\right)^{2} / 2+\delta s_{2} B$ in period $t=2$ with probability $\theta$, and $-\left(s_{2}\right)^{2} / 2+\beta \delta s_{2} B$ with probability $1-\theta$. This implies that the partially naive agent expects to choose a search level $\tilde{s}_{2}(\theta)$ which is characterized by

$$
\begin{gathered}
\tilde{s}_{2}=\delta B \text { with probability } \theta \\
\tilde{s}_{2}=\beta \delta B \text { with probability } 1-\theta .
\end{gathered}
$$

Furthermore, in period 1 the partially naive agent expects to be offered a secondperiod wage

$$
\begin{aligned}
\tilde{w}_{2}^{P N} & =-\frac{1}{2}(\delta B)^{2} \text { with probability } \theta \\
\tilde{w}_{2}^{P N} & =-\frac{1}{2}(\beta \delta B)^{2} \text { with probability } 1-\theta .
\end{aligned}
$$

The agent's behavior in $t=1$ is determined by his perceptions of future outcomes, not their true realizations.

This yields

Lemma 4 A partially naive agent with $\theta \in(0,1)$

- exerts less search effort in the first period than in the second, i.e. $s_{1}^{P N}<s_{2}^{P N}$.

- receives a first-period wage that is lower than the first-period negative search benefit, i.e. $w_{1}^{P N}<\frac{1}{2}\left(s_{1}^{P N}\right)^{2}-\beta \delta s_{1}^{P N} B$.

Moreover, in the first period a higher extent of naivete lets an agent search more and receive a higher wage, i.e. $d s_{1}^{P N} / d \theta>0$ and $d w_{1}^{P N} / d \theta>0$.

The proof can be found in the Appendix.

Finally, Proposition 4 explores the effect of an agent's naivete on his realized utility.

Proposition 4 The utility of a partially naive agent is positive and strictly increasing in $\theta$.

The proof can be found in the Appendix.

Proposition 4 indicates that our results on the differences between a sophisticated and a fully naive agent hold monotonically, for any value $\theta \in(0,1)$. 


\section{Discussion and Conclusion}

We have shown that present-biased agents can benefit from being naive - in a situation where they conduct on-the-job search and firms cannot commit to long-term contracts. Moreover, naive agents search more extensively, which might increase the efficiency of a labor market with frictions.

To conclude, we will discuss potential implications of our results. First, shortterm contracts may actually be advantageous for employees (compared to long-term contracts). For a sophisticated agent, nothing would change if the principal was able to commit to a long-term contract. A naive agent, however, would be worse off with this possibility. Then, the principal could exploit the agent's false expectations about future search effort while avoiding false expectations about future wages (which, in our current setting, a naive agent perceives to be lower than they actually turn out to be). Therefore, in situations where a lack of commitment by firms leads to a negative wage premium, we would expect naive agents to search more and earn higher wages than sophisticated agents.

Second, our results might be used to generate new insights on the effects of a minimum wage. Whereas a sufficiently high minimum wage in our setup benefits all agents, an intermediate level can harm a naive and benefit a sophisticated agent: Assume there is a minimum wage that exceeds the second-period wage a naive agent expects but is below the second (and first) period wage he actually receives. Then, a naive agent wrongfully anticipates a rent in the second period and consequently accepts a higher wage reduction in the first. In addition, his first-period search effort goes down. A sophisticated agent, on the other hand, would at all levels (weakly) benefit from a minimum wage. 


\section{Appendix}

Proof of Lemma 1. Conditional on not having received an outside job offer before, and conditional on having accepted the principal's employment offer at the beginning of $t=1$, the agent chooses search effort to maximize,

$$
-\frac{1}{2}\left(s_{1}\right)^{2}+\delta\left\{s_{1} B+\left(1-s_{1}\right)\left[w_{2}^{T C}-\frac{1}{2}\left(s_{2}^{T C}\right)^{2}+\delta\left(s_{2}^{T C} B+\left(1-s_{2}^{T C}\right) w_{3}^{T C}\right)\right]\right\}
$$

however taking into account $w_{3}^{T C}=0$ and $w_{2}^{T C}=\frac{1}{2}\left(s_{2}^{T C}\right)^{2}-\delta s_{2}^{T C} B$. Therefore, the problem boils down to maximizing $-\frac{1}{2}\left(s_{1}\right)^{2}+\delta s_{1} B$, yielding $s_{1}^{T C}=\delta B$, as well as $w_{1}^{T C}=\frac{1}{2}\left(s_{1}^{T C}\right)^{2}-\delta s_{1}^{T C} B<0$, hence $s_{1}^{T C}=s_{2}^{T C}$ and $w_{1}^{T C}=w_{2}^{T C}$.

Proof of Lemma 2. $\quad s_{1}^{S}$ maximizes

$$
\begin{aligned}
U_{1}^{S} & =-\frac{1}{2} s_{1}^{2}+\beta \delta\left\{s_{1} B+\left(1-s_{1}\right)\left[w_{2}-\frac{1}{2} s_{2}^{2}+\delta s_{2} B\right]\right\} \\
& =-\frac{1}{2} s_{1}^{2}+\beta \delta\left\{s_{1} B+\left(1-s_{1}\right)(1-\beta) \beta \delta^{2} B^{2}\right\}
\end{aligned}
$$

hence

$$
s_{1}^{S}=\beta \delta\left[B-\delta s_{2}^{S} B(1-\beta)\right] .
$$

It follows that $s_{1}^{S}<s_{2}^{S}=\beta \delta B$.

$w_{1}^{S}$ is set to satisfy $U_{1}^{S}=w_{1}^{S}-\frac{1}{2}\left(s_{1}^{S}\right)^{2}+\beta \delta\left[s_{1}^{S} B+\left(1-s_{1}^{S}\right) \delta s_{2}^{S} B(1-\beta)\right]=0$, hence

$$
w_{1}^{S}=\frac{1}{2}\left(s_{1}^{S}\right)^{2}-\beta \delta\left[s_{1}^{S} B+\left(1-s_{1}^{S}\right) \delta s_{2}^{S} B(1-\beta)\right]<\frac{1}{2}\left(s_{1}^{S}\right)^{2}-\beta \delta s_{1}^{S} B .
$$

Proof of Lemma 3 A fully naive agent perceives his first-period utility to be

$$
\tilde{U}_{1}^{N}=w_{1}-\frac{1}{2}\left(s_{1}\right)^{2}+\beta \delta\left\{s_{1} B+\left(1-s_{1}\right)\left[\tilde{w}_{2}^{N}-\frac{1}{2}\left(\tilde{s}_{2}^{N}\right)^{2}+\delta\left(\tilde{s}_{2}^{N} B+\left(1-\tilde{s}_{2}^{N}\right) w_{3}^{N}\right)\right]\right\} .
$$

Making use of $\tilde{w}_{2}^{N}=\frac{1}{2}\left(\tilde{s}_{2}^{N}\right)^{2}-\delta \tilde{s}_{2}^{N} B$ and $w_{3}=0$, this becomes

$$
\tilde{U}_{1}^{N}=w_{1}-\frac{1}{2}\left(s_{1}\right)^{2}+\beta \delta s_{1} B .
$$

The Lemma immediately follows.

Proof of Proposition 1 . 
As shown in Lemma 2, period-1 search effort of a sophisticated agent equals

$$
s_{1}^{S}=\beta \delta B\left[1-\delta s_{2}^{S}(1-\beta)\right]=0 .
$$

As shown in Lemma 3 , period-1 search effort of a fully naive agent equals

$$
s_{1}^{N}=\beta \delta B
$$

Given $s_{2}^{S}>0$, the Proposition immediately follows.

\section{Proof of Proposition 2.}

The naive agent's realized utility level in period $t=1$ amounts to

$$
\begin{aligned}
U_{1}^{N}= & w_{1}^{N}-\frac{1}{2}\left(s_{1}^{N}\right)^{2} \\
& +\beta \delta\left\{s_{1}^{N} B+\left(1-s_{1}^{N}\right)\left[w_{2}^{N}-\frac{1}{2}\left(s_{2}^{N}\right)^{2}+\delta\left(s_{2}^{N} B+\left(1-s_{2}^{N}\right) w_{3}^{N}\right)\right]\right\} .
\end{aligned}
$$

Taking into account $w_{1}^{N}=\frac{1}{2}\left(s_{1}^{N}\right)^{2}-\beta \delta s_{1}^{N} B, w_{2}^{N}=\frac{1}{2}\left(s_{2}^{N}\right)^{2}-\beta \delta s_{2}^{N} B$ and $w_{3}^{N}=0$,

$$
U_{1}^{N}=\beta(1-\beta) \delta^{2}\left(1-s_{1}^{N}\right) s_{2}^{N} B>0
$$

\section{Proof of Proposition 3 .}

Recall that first-period wages are

- $w_{1}^{N}=\left(s_{1}^{N}\right)^{2}-\beta \delta s_{1}^{N} B$

- $w_{1}^{S}=\left(s_{1}^{S}\right)^{2}-\beta \delta\left[s_{1}^{S} B+\left(1-s_{1}^{S}\right) \delta s_{2}^{S} B(1-\beta)\right]$.

Taking into account that $s_{1}^{N}=\beta \delta B$ and $s_{1}^{S}=\beta \delta B\left[1-\delta^{2} \beta(1-\beta) B\right]$, those amount to

- $w_{1}^{N}=-\frac{1}{2}(\beta \delta B)^{2}$

- $w_{1}^{S}=-\beta^{2} \delta^{2} B^{2}\left[\frac{1}{2}\left(1-\beta \delta^{2} B(1-\beta)\right)^{2}+\delta(1-\beta)\right]$

Hence

$$
\begin{aligned}
w_{1}^{N}-w_{1}^{S} & =-\frac{1}{2}(\beta \delta B)^{2}+\beta^{2} \delta^{2} B^{2}\left[\frac{1}{2}\left(1-\beta \delta^{2} B(1-\beta)\right)^{2}+\delta(1-\beta)\right] \\
& =\beta^{2} \delta^{3} B^{2}(1-\beta)\left[1-\beta \delta B+\frac{1}{2} \beta^{2} \delta^{3} B^{2}(1-\beta)\right]>0 \text { if } \beta \delta B<1 .
\end{aligned}
$$


There, note that $\beta \delta B<1$ holds in order to always guarantee.

Furthermore, $s_{1}^{S}<s_{1}^{N}$ (see Proposition 1), hence a naive agent is more likely to receive a new job offer - which reduces the principal's profits because of $\underline{\pi}<\pi$.

Proof of Lemma 4. A partially naive agent perceives his first-period utility to be (already taking into account $w_{3}=0$ )

$$
\tilde{U}_{1}^{P N}=w_{1}-\frac{1}{2}\left(s_{1}\right)^{2}+\beta \delta\left\{s_{1} B+\left(1-s_{1}\right)\left[\theta \cdot 0+(1-\theta) \beta \delta^{2} B^{2}(1-\beta)\right]\right\} .
$$

The first-order condition yields

$$
s_{1}^{P N}=\beta \delta\left[B-(1-\theta) \beta \delta^{2} B^{2}(1-\beta)\right]<s_{2}^{P N}=\beta \delta B,
$$

with

$$
\frac{d s_{1}^{P N}}{d \theta}=\beta^{2} \delta^{3} B^{2}(1-\beta)>0 .
$$

Moreover,

$$
\begin{aligned}
w_{1}^{P N} & =\frac{1}{2}\left(s_{1}^{P N}\right)^{2}-\beta \delta\left[s_{1}^{P N} B+\left(1-s_{1}^{P N}\right)(1-\theta) \beta \delta^{2} B^{2}(1-\beta)\right] \\
& <\frac{1}{2}\left(s_{1}^{P N}\right)^{2}-\beta \delta s_{1}^{P N} B
\end{aligned}
$$

and

$$
\frac{d w_{1}^{P N}}{d \theta}=\beta^{2} \delta^{3} B^{2}(1-\beta)\left(1-\beta \delta B+(1-\theta) \beta^{2} \delta^{3} B^{2}(1-\beta)\right)>0
$$

\section{Proof of Proposition 4 .}

A partially naive agent realized period-1 utility equals

$$
\begin{aligned}
U_{1}^{P N}= & w_{1}^{P N}-\frac{1}{2}\left(s_{1}^{P N}\right)^{2} \\
& +\beta \delta\left\{s_{1}^{P N} B+\left(1-s_{1}^{P N}\right)\left[w_{2}^{P N}-\frac{1}{2}\left(s_{2}^{P N}\right)^{2}+\delta\left(s_{2}^{P N} B+\left(1-s_{2}^{P N}\right) w_{3}^{P N}\right)\right]\right\} .
\end{aligned}
$$

Taking into account $w_{1}^{P N}=\frac{1}{2}\left(s_{1}^{P N}\right)^{2}-\beta \delta\left[s_{1}^{P N} B+\left(1-s_{1}^{P N}\right)(1-\theta) \beta \delta^{2} B^{2}(1-\beta)\right]$, $w_{2}^{P N}=\frac{1}{2}\left(s_{2}^{P N}\right)^{2}-\beta \delta s_{2}^{P N} B, s_{2}^{N}=\beta \delta B$ and $w_{3}^{P N}=0$,

$$
U_{1}^{P N}=\theta\left(1-s_{1}^{P N}\right) \beta^{2} \delta^{3} B^{2}(1-\beta)
$$


with

$$
\begin{aligned}
\frac{d U_{1}^{P N}}{d \theta} & =\left(1-s_{1}^{P N}\right) \beta^{2} \delta^{3} B^{2}(1-\beta)-\frac{d s_{1}^{P N}}{d \theta} \theta \beta^{2} \delta^{3} B^{2}(1-\beta) \\
& =\beta^{2} \delta^{3} B^{2}(1-\beta)\left[1-\beta \delta B+(1-2 \theta) \beta^{2} \delta^{3} B(1-\beta)\right] \\
& \geq \beta^{2} \delta^{3} B^{2}(1-\beta)\left[1-\beta \delta B-\beta^{2} \delta^{3} B(1-\beta)\right] \\
& =\beta^{2} \delta^{3} B^{2}(1-\beta)\left[1-\beta \delta B\left(1+\beta \delta^{2}(1-\beta)\right)\right] \\
& \geq \beta^{2} \delta^{3} B^{2}(1-\beta)[1-\delta B \beta(1+\beta(1-\beta))] \\
& =\beta^{2} \delta^{3} B^{2}(1-\beta)\left[1-\delta B\left(1-(1-\beta)\left(1-\beta^{2}\right)\right)\right] \\
& >0
\end{aligned}
$$

where the latter follows from $\delta B \leq 1$. 


\section{References}

Martin Biewen and Susanne Steffes. Unemployment persistence: Is there evidence for stigma effects? Economics Letters, 106:188-190, 2010. 1, 2

Melissa Bjelland, Haltiwanger John Fallick, Bruce, and Erika McEntarfer. Employerto-employer flows in the united states: Estimates using linked employer-employee data. pages 493-505], volume $=29$, number $=4$, journal $=$ Journal of Business \& Economic Statistics, 2011. 1, 3.3

Simon Board and Moritz Meyer-Ter-Vehn. Relational contracts in competitive labour markets. The Review of Economic Studies, 82(2):490-534, 2015. ISSN 0034-6527. doi: 10.1093/restud/rdu036. 1, 2, 3

Yoon Jik Cho and Gregory B. Lewis. Turnover intention and turnover behavior. Review of Public Personnel Administration, 32(1):4-23, 2011. doi: 10.1177/0734371X11408701. 1]

Federica Cingano and Alfonso Rosolia. People i know: Job search and social networks. Journal of Labor Economics, 30(2):291-332, 2012. 1, 2

Stefano DellaVigna. Psychology and economics: Evidence from the field. Journal of Economic Literature, 47(2):315-372, 2009. 1

Stefano DellaVigna and M. Daniele Paserman. Job search and impatience. Journal of Labor Economics, 23(3):527-588, 2005. 1, 3.1.

Kfir Eliaz and Ran Spiegler. Contracting with diversely naive agents. The Review of Economic Studies, 73(3):689, 2006a. ISSN 0034-6527. doi: 10.1111/j.1467-937X. 2006.00392.x. URL +http://dx.doi.org/10.1111/j.1467-937X.2006.00392. x. 1, 2

Kfir Eliaz and Ran Spiegler. Contracting with diversely naive agents. The Review of Economic Studies, 73(3):689-714, 2006b. 1, 2

Florian Englmaier, Matthias Fahn, and Marco A. Schwarz. Long-term employment relations when agents are present biased. 2016. 1, 2, 2

Bruce C. Fallick and Charles A. Fleischman. The importance of employer-toemployer flows in the u.s. labor market. 2001. 1, 3.3

Pieter A. Gautier, Coen N. Teulings, and Aico Van Vuuren. On-the-job search, mismatch and efficiency. Review of Economic Studies, 77(1):245-272, 2010. 1 
Scott M. Gilpatric. Present-biased preferences, self-awareness and shirking. Journal of Economic Behavior \& Organization, 67(3):735-754, 2008. 1, 2

Joyce K. Hahn, Henry R. Hyatt, Hubert P. Janicki, and Stephen R. Tibbets. Jobto-job flows and earnings growth. American Economic Review, 107(5):358-363, 2017. 3.3

John Haltiwanger, Stefano Scarpetta, and Helena Schweiger. Cross country differences in job reallocation: The role of industry, firm size and regulations. Labour Economics, 26:11-25, 2014. ISSN 0927-5371. doi: 10.1016/j.labeco.2013.10.001. 3.3

Paul Heidhues and Botond Kőszegi. Exploiting Naïvete about Self-Control in the Credit Market. American Economic Review, 100(5):2279-2303, December 2010. ISSN 0002-8282. [1

Allesandro Ispano and Peter Schwardmann. Competition over cursed consumers. 2017. 1

Botond Koszegi. Behavioral contract theory. Journal of Economic Literature, 52 (4):1075-1118, 2014. 1, 2

David Laibson. Golden eggs and hyperbolic discounting*. The Quarterly Journal of Economics, 112(2):443-478, 1997. ISSN 0033-5533. doi: 10.1162/ 003355397555253. 1, 2

Dale T. Mortensen. Equilibrium unemployment with wage posting: Burdettmortensen meets pissarides. 2000. 1

G. Moscarini. Job matching and the wage distribution. Econometrica, 73:481-516, 2005. 1

Andreas Mueller. On-the-job search and wage dispersion: New evidence from time use data. Economics Letters, 109(2):124-127, 2010. ISSN 0165-1765. 1, 2

Eva Nagypal. Amplification of productivity shocks: Why donât vacancies like to hire the unemployed? 2005. 1, 2

Eva Nagypal. Worker reallocation over the business cycle: The importance of employer-to-employer transitions. 2008. 1, 3.3

Ted O'Donoghue and Matthew Rabin. Doing it now or later. The American Economic Review, 89(1):103-124, 1999a. ISSN 0002-8282. 2, 2 
Ted O'Donoghue and Matthew Rabin. Incentives for procrastinators. The Quarterly Journal of Economics, 114(3):769-816, 1999b. ISSN 0033-5533. doi: 10.1162/ 003355399556142. 1

M. Daniele Paserman. Job search and hyperbolic discounting: Structural estimation and policy evaluation. The Economic Journal, 118(531):1418-1452, 2008. ISSN 1468-0297. 1, 3.1.

C.A. Pissarides. Search unemployment with on-the-job serach. Review of Economic Studies, 61:457-475, 1994. 1

Christopher A. Pissarides. Loss of skill during unemployment and the persistence of employment shocks. Quarterly Journal of Economics, 107:1371-1391, 1992. 1. 2 